\title{
Michael R. Gottfredson and Travis Hirschi
}

\author{
Modern Control Theory and the Limits of Criminal Justice. New York, NY: Oxford University Press, \\ 2020
}

\author{
Dirk Enzmann ${ }^{1}$
}

Accepted: 12 February 2022 / Published online: 25 February 2022

(c) The Author(s) 2022

Thirty years after their enormously influential book " $A$ general theory of crime" (GTC; Gottfredson \& Hirschi, 1990) Michael Gottfredson and Travis Hirschi now did publish a sequel: "Modern control theory and the limits of criminal justice" (MCT). The GTC is one of the most important criminological theories. The theory has been applied or tested in thousands of criminological studies around the world, and in the Western world there is virtually no modern textbook without reference to the GTC. Sometimes the theory is reduced to and by many it is simply referred to as the "Self-control Theory" although the original GTC is based on two legs: (1) A specific definition of crime as "acts of force or fraud undertaken in the pursuit of self-interest" (GTC, 15) and (2) the propensity of the actor: "This is the problem of self-control, the differential tendency of people to avoid criminal acts whatever the circumstances in which they find themselves." (GTC, 87).

In their new work, the authors explicitly do not intend to revise their GTC as already described in their first book: "The control theory justified and explicated in that workits structure, logic, and explicit and implicit predictionsshould stand as stated." (MCT, x) Instead, in part 1 they take the opportunity to correct shortcomings of their older work where language has been unclear (or where they did not follow the dictates of their own theory), to counter some critiques of their theory that accumulated since the publication of the GTC, and to respond to developments in theory and research with which they disagree. In part 2 they explore and delineate the implications of their work for the justice system and for the development of a theory-based public

Dirk Enzmann

dirk.enzmann@uni-hamburg.de

1 University of Hamburg, Hamburg, Germany policy, thereby updating and expanding the last chapter of their 1990 book considerably.

In the first part, Gottfredson and Hirschi explicate the GTC as previously stated and review and respond to a selection of theoretical and empirical issues they regard as the most important: the relationship of age and crime (an issue that can be said to be the starting point of the development of their theory), the question of stability of the individual propensity to react to desires, needs, and temptations and the connection of this propensity to situational causes of crime, the challenges and methodological issues of research that set out to test their theory, and some of the most disputed and most important conceptual issues of their theory which are the identity of (or connection between) social control, social bonding, self-control and morality.

\section{The Concepts of Crime and Self-control}

Two examples of clarifications are the concepts of crime and of self-control that are at the root of the GTC: Whereas in their 1990 book the definition of crime refers to "actions of force or fraud undertaken in the pursuit of self-interest" (GTC, 15), in MCT Gottfredson and Hirschi define crime as "behaviors (events) that provide momentary or immediate satisfactions but have negative consequences subsequently" (MCT, 11), thereby not only avoiding a legal definition of crime more clearly, but also removing the motivation from the definition of crime that has been criticized by Wikström and Treiber (2007). Gottfredson and Hirschi note that this definition of crime excludes behaviors that (although criminal) provide long term gains: "Some terrorist acts, involving homicide and assault, would not fall under the definition of crime for control theory because these acts may be undertaken precisely with the long term in view ..." (MCT, 13). However, this improved definition may exclude not only acts 
of political extremism but a broader range of criminal acts such as corporate or white-collar crimes which are carefully planned with long-term gains in view. These crimes are too costly to society to dismiss them as too "few in number and of limited interest to a behavioral theory." (Hirschi \& Gottfredson, 2000, p. 65) It is telling that in MCT the issue of white-collar crime is virtually lacking, whereas in the GTC book Gottfredson and Hirschi did devote a whole chapter on this subject: "In fact, our general theory of crime accounts for the frequency and distribution of white-collar crime in the same way as it accounts for the frequency and distribution of all other crimes." (GTC, 181).

The development of the definition of criminality and self-control is more complex, showing that Gottfredson and Hirschi struggled to arrive at a definition that avoids the (mis)understanding that self-control is an individual propensity to crime. "Criminality" is defined differently in their publications (and sometimes within one publication). In a chapter published in 1986 Gottfredson and Hirschi define criminality as the propensity to commit criminal acts:

Crimes are short term, circumscribed events that presuppose a peculiar set of necessary conditions (e.g. activity, opportunity, adversaries, victims, goods). Criminality, in contrast, refers to stable differences across individuals in the propensity to commit criminal (or equivalent) acts. Accordingly, criminality is only one element in the causal configuration leading to a criminal act and criminal acts are, at best, imperfect measures of criminality. (Hirschi \& Gottfredson, 1986, 58; compare GTC, 137)

In MCT they stipulate clearly that self-control is not a propensity for crime: "We define self-control as the tendency to consider the negative consequences of an act. It is, as such, not a propensity to commit crime" (MCT, 43, accentuation by the authors) and criticize those who believe self-control was a propensity to commit crime. In their 1990 book they describe how they developed the concept of self-control:

Our decision to ascribe stable individual differences in criminal behavior to self-control was made only after considering several alternatives, one of which (criminality) we had used before ... An obvious alternative is the concept of criminality. The disadvantages of that concept, however, are numerous. First, it connotes causation or determinism, a positive tendency to crime that is contrary to the classical model and, in our view, contrary to the facts. Whereas self-control suggests that people differ in the extent to which they are restrained from criminal acts, criminality suggests that people differ in the extent to which they are compelled to crime. (GTC 1990, 87f.)
However, a section of the 1990 book (pp. $134 \mathrm{ff}$.) is largely a copy of the 1986 article quoted above in which the term "criminality" has simply been replaced by "selfcontrol" throughout (GTC, 137). This may have contributed to the understanding of many readers that self-control can be equated with criminality. The new book clearly helps to clarify what Gottfredson and Hirschi actually mean by propensity and self-control:

In our theory, self control is not regarded as a predisposition to crime, a propensity for crime, or a personality trait for crime and delinquency. Rather, self control is understood as an inclination to focus on the short term rather than the long term ... Therefore, our selfcontrol theory is a choice theory rather than a deterministic one. (MCT, 6f.)

This clarification of the concepts of crime and selfcontrol in MCT is important. Textbooks on criminology explaining the GTC that quote the definition of crime in the 1990 book (GTC, 15) or that follow Akers' understanding that "G\&H use 'low self-control' and 'high self-control' simply as labels for this differential propensity to commit crime" (Akers, 1991, p. 204) need to be rewritten.

\section{Social Bonding, Self-control and Morality}

According to Gottfredson and Hirschi morality and selfcontrol overlap: "When it is said that our general theory of crime lacks the dimension of morality ... we disagree. ... we cannot imagine our self-control-construct, and the way it emerges in socialization, to not incorporate a fundamental notion of morality." (MCT, 123). The logic of their argument is straightforward: Social bonds and self-control "should be taken to be the same thing" (MCT, 100). Selfcontrol and beliefs (an element of the individuals' bond to society) are produced in the same way, items of beliefs and moral values measure the same thing, and measures of social control (the strength of bonds to people and institutions of conventional society) are ultimately measures of self-control. (MCT, 122) Hence, moral beliefs are part of their conception of self-control.

According to Gottfredson and Hirschi "self-control ... is established in significant part by concern for opinions of others that thereby creates costs to the actor's behavior." (MCT, 39) However, although it is convincing that development of self-control is enhanced by the development of morality, a development of non moral self-control (Hartmann et al., 2018) is possible: Self-control can also be established by non-social mechanisms if individuals learn that impulsive and risky behaviors come with consequences detrimental to their self-interest. Gottfredson and Hirschi criticize the "ancient" distinction of moral and calculative control, 
according to which the calculation of costs and benefits comes into play if the first line of defense (moral values and principles) fails. (MCT, 123) But is a person who is not bound to the society and conventional morality but able to anticipate the long-term consequences of his or her acts and who decides to commit crimes for personal or collective gains (such as the bureaucrats, businessmen, politicians, and military convicted at the Nuremberg Trials, to mention only high ranking criminals from the past) not the most effective and dangerous criminal?

Although Gottfredson and Hirschi are aware that since a long time reviewers criticize them for "too strong" or "sweeping" assertions (Hirschi \& Gottfredson, 1983, p. 554) they still insist on saying that measures of social control and morality are ultimately measures of self-control. Perhaps the development of their intellectual career can explain the radical and extreme positions on these issues and their resistance to differentiate between morality and self-control: Gottfredson and Hirschi's research started with a review of the fundamental assumptions of cultural deviance/ learning theories, anomie theories and control theories (for an early account see Kornhauser, 1978) applied to common crimes characteristic for juvenile delinquency which resulted in the development of an alternative general control theory "meant to explain all crime, at all times." (GTC, p. 117) Surely, parsimony matters. But to broaden the concept of self-control to include social bonds and morality impedes to advance a theory of action (or choice theory) which requires to study the mechanisms in the interaction of the individual (personal morality and control) and its contexts (morality and controls of the situation) that result in criminal acts (see Wikström, 2010).

\section{Public Policy and the Criminal Justice System}

In the second part of the book the authors address the implications of their theory for public policy and the criminal justice system for the reduction and prevention of crime. Focusing on developments of deterrence strategies, sentencing and prisons, policing strategies, situational crime prevention, and the question of immigration and crime they address important issues, bringing together and updating contributions that have previously been published in several articles and book chapters (some sections of this part are repetitive because portions of chapters 8,9 , and 11 are based on previous publications). "Discussions of theory and policy must be closely intertwined, because good theory abounds with policy implications, and good policy is guided by sound theory." (Piquero, 2010, p. 66) This is exactly the strength of their approach: With concrete examples Gottfredson and Hirschi evaluate public policy and the effectiveness (i.e. the limits) of the criminal justice system using basic assumptions of control theory to predict success or shortcomings of various prevention and intervention strategies, thereby simultaneously evaluating their theory and demonstrating that theoretical work, conceptual arguments and a sound theory are indispensable tools for effective practice. Although the focus is on the US, the findings and arguments are of general interest and highly relevant for public policies and criminal justice systems in other parts of the world, as well.

In this respect the findings on immigration and crime are especially interesting: Gottfredson and Hirschi demonstrate that classical sociological theories (e.g. culture conflict theories) are wrong on the facts (as to the nature of crime and immigration); they present not only theoretical but also empirical counter arguments to positions in misleading political rhetoric and demonstrate the necessity for multilevel studies integrating area and individual level data to avoid the ecological fallacy trap. Contrary to differential association, subculture, and strain theories as well as in contrast to public and political opinion, first and second generation immigrants (irrespective of being legal or undocumented) show lower crime rates, less substance use and better adaptation outcomes than natives. This is what control theory would predict because immigration requires comparatively high levels of self-control and immigrants (especially undocumented) are motivated to avoid contacts with the police and to improve their lives by work and adaptation to the host culture.

As a general conclusion Gottfredson and Hirschi argue that crime prevention should not primarily be relegated to the police and the criminal justice system. Prevention would be far more effective if it would invest more in informal social controls and support for caregivers to foster self-control of children already in pre-school years (which will also enhance the likelihood of positive life outcomes in general) and less in state-based formal sanctioning systems that are not able to deter those with low self-control but only those who are already deterred by informal control and anticipation of negative long-term consequences. Likewise, situational crime prevention targeting the low self-control of offenders will be more effective with less collateral damage to cohesion and trust than more police with greater policing powers. While this is convincing with regard to ordinary crime, will this also hold for serious adult crime and criminals with low morality but higher levels of self-control? As long as crime is youthful behavior (MCT, 74) the arguments are convincing and it would make sense to "favor treating adults more akin to how we treat juveniles." (MCT, footnote 2 to page 145) In this respect it is correct that "we invest in the wrong end of the age distribution, especially in police and prisons." (MCT, 224) But crimes with serious damage to our society such as white-collar crime, crime against humanity, atrocity crime, war crime, or terrorism are clearly not youth crimes and most likely cannot be explained 
in the same way. We know much more about juveniles and their crimes than about adult crime which we can only estimate using official statistics because of a lacuna of research regarding valid self-report studies of adult crime.

\section{Recommendation}

"Modern Control Theory and the Limits of Criminal Justice" is excellent and a "must read" for scholars, students, and practitioners alike. It is clearly worth studying-reading is not enough - even for those who are already familiar with the 1990 book. I also recommend it to scholars subscribing to a critical criminology claiming that it would be futile to look for a general theory because the definition and nature of crime varies across time, cultures, and societies: Gottfredson and Hirschi remind us that such arguments are falsely based on the idea "that crime is merely a sociological construct." (MCT, 222) Their definition of crime and delinquency in behavioral terms avoids this "theoretical problem" trap. Critical criminologists could perhaps embrace control theory for one reason: "Fostering self-control and bonding minimizes the need for and probability of severe state-based criminal sanctions in the long term. ... In today's terms, our version of control theory ... could never logically be a basis for mass incarceration or greatly enhanced policing." (MCT, 226).

However, a caveat for the uninitiated reader: The book requires close reading and some parts of the theory chapters are not easy to understand (or easy to misunderstand). At times a deeper understanding of the arguments requires a detailed knowledge of the history of the debate. It may be that you will have to read the whole book to completely understand the preface (that actually is intended to introduce the reader to the issues discussed). Although the book helps to see what Michael Gottfredson and Travis Hirschi really intend to say on issues such as the definition of crime and self-control or the role of age in the life-course, there will still be disagreement. Hence, the book is not only thought provoking but will also provoke opposition, as some reservations raised by Robert Sampson (1992) and Charles Tittle (1991) in their reviews of the 1990 book will presumably be raised again (e.g. the neglect of intra-individual developmental change, the issue of the interaction of social controls and self-control, the "unexplained" direct effect of age on crime, or the role of self-control for white-collar crimes. But even to those who will not agree: The reading of the book will be rewarding because it forces to think (again) and (more) deeply over basic concepts and empirical issues. Last and not least: The book deserves great attention in the fields of crime prevention, policing, and criminal justice-readers who are practitioners of public policy and the criminal justice system possibly have to reconsider the scientific basis of their work.

Funding Open Access funding enabled and organized by Projekt DEAL.

Open Access This article is licensed under a Creative Commons Attribution 4.0 International License, which permits use, sharing, adaptation, distribution and reproduction in any medium or format, as long as you give appropriate credit to the original author(s) and the source, provide a link to the Creative Commons licence, and indicate if changes were made. The images or other third party material in this article are included in the article's Creative Commons licence, unless indicated otherwise in a credit line to the material. If material is not included in the article's Creative Commons licence and your intended use is not permitted by statutory regulation or exceeds the permitted use, you will need to obtain permission directly from the copyright holder. To view a copy of this licence, visit http://creativecommons.org/licenses/by/4.0/.

\section{References}

Akers, R. L. (1991). Self-control as a general theory of crime. Journal of Quantitative Criminology, 7, 201-211.

Gottfredson, M. R., \& Hirschi, T. (1990). A general theory of crime. Stanford University Press.

Hartmann, W., Meindl, P., Mooijman, M., \& Graham, J. (2018). Morality and self-control: How they are intertwined and where they differ. Current Directions in Psychological Science, 27, 286-291.

Hirschi, T., \& Gottfredson, M. R. (1983). Age and the explanation of crime. American Journal of Sociology, 89, 552-584.

Hirschi, T., \& Gottfredson, M. R. (1986). The distinction between crime and criminality. In T. F. Hartnagel \& R. A. Silverman (Eds.), Critique and explanation: Essays in honor of gwynn nettler (pp. 55-69). Transaction Publishers.

Hirschi, T., \& Gottfredson, M. R. (2000). In defense of self-control. Theoretical Criminology, 4, 55-69.

Kornhauser, R. R. (1978). Social sources of delinquency: An appraisal of analytic models. The University of Chicago Press.

Piquero, A. R. (2010). A general theory of crime and public policy. In H. D. Barlow \& S. H. Decker (Eds.), Criminology and public policy: Putting theory to work (pp. 66-83). Temple University Press.

Sampson, R. J. (1992). [Book Reviews] A general theory of crime. By Michael R Gottfredson \& Travis Hirschi. Social Forces, 71, $545-546$.

Tittle, C. R. (1991). [Book Reviews] A general theory of crime. By Michael R. Gottfredson and Travis Hirschi. American Journal of Sociology, 96, 1609-1611.

Wikström, P.-O. (2010). Explaining crime as moral actions. In S. Hitlin \& S. Vaisey (Eds.), Handbook of the sociology of morality (pp. 211-239). Springer.

Wikström, P.-O., \& Treiber, K. (2007). The role of self-control in crime causation. European Journal of Criminology, 4, 237-264. 